\title{
Editorial Annals of Regional Science
}

\author{
Martin Andersson ${ }^{1,2,3,4} \cdot$ Hong Sok Kim ${ }^{5}$ Janet Kohlhase ${ }^{6}$ \\ Published online: 3 January 2020 \\ ๑) Springer-Verlag GmbH Germany, part of Springer Nature 2020
}

There is no tradition in Annals of Regional Science that the editors write editorials. However, as of 2020, the editors will each year write an editorial in which we report as well as reflect on recent developments of the journal. We hope that this will be of interest for our readers. This editorial is the first one and marks the start of the strategy to write a yearly editorial.

We, i.e., Martin Andersson (Sweden), Hong Sok Kim (South Korea) and Janet Kohlhase (USA), are by some standards a rather new constellation of editors-inchief (EICs). Janet Kohlhase became an editor in 2011, replacing professor Roger Stough. ${ }^{1}$ Martin Andersson joined as editor in 2014 and replaced professor Börje Johansson. Hong Sok (Brian) Kim became an editor in 2019 by replacing professor Euijune Kim. The former EICs continue to be part of the journal in the capacity as members of the advisory board of former editors. We are all delighted to serve as EICs and are committed to maintain as well as to further develop the journal's tradition of publishing high-quality and influential research that pushes the field of regional science forward.

\footnotetext{
${ }^{1}$ Sadly, professor Roger Stough passed away in September 2019. He was as of significant importance for our journal and served as one of its editors-in-chief for over 15 years (1994-2011). An In Memoriam was published last year documenting his contribution to the journal as well as the wider research community in regional science (Kohlhase 2019).
}

Martin Andersson

martin.andersson@bth.se

1 Department of Industrial Economics, Blekinge Institute of Technology (BTH), Karlskrona, Sweden

2 Swedish Entrepreneurship Forum, Sockholm, Sweden

3 Research Institute of Industrial Economics, Stockholm, Sweden

4 CIRCLE, Lund University, Lund, Sweden

5 Department of Agricultural Economics and Rural Development, Seoul National University, Seoul, Korea

6 Department of Economics, University of Houston, Houston, US 


\section{Some recent developments of the journal}

\subsection{Expanded and renewed board of associate editors}

In recent years, the board of associate editors of the journal has been expanded and renewed. Members of the board support with reviewing papers, finding suitable reviewers and are, at times, consulted before decisions. The board of associate editors currently consists of 36 members. They are all at least associate professors that are active in regional science research and represent a mix of younger and older established researchers from different countries. The current board represents more than 10 countries in North America, Europe, Asia and Australia. Members of the board provide critical support for the development of the journal.

\subsection{Rising impact factor in recent years}

The impact factor (IF) of a journal is a widely used indicator of a journal's prestige and overall impact. Although there is plenty of criticism to the ways in which the IF is computed, it is still one of the main criteria used when scholars, in particular scholars in the early stage of their careers, choose which journals to target in their respective fields.

We are happy to report that the IF of Annals of Regional Science has developed in a positive way in recent years. For instance, in 2015 the IF was 0.571 , whereas it reached 1.075 according to the journal citation report in 2018, published through the Web of Science. We EICs also witness an increasing quality of submitted papers, and this is a development that is very much welcomed. It is a reflection of the fact that Annals of Regional Science continues to attract influential research papers of high quality, as well as that the efforts of colleagues in our community to secure quality and relevance of submitted papers by taking on the role as reviewers pay off.

\subsection{Continued broad range of topics in published papers}

As readers of Annals of Regional Science are certainly aware of, the journal is broad in terms of its aims and scope. The stated objective is that the journal should publish papers "which make a new or substantial contribution to the body of knowledge in which the spatial dimension plays a fundamental role, including regional economics, resource management, location theory, urban and regional planning, transportation and communication, population distribution and environmental quality." This naturally implies that submissions as well as published papers can cover a wide array of topics as well as use different types of methodologies. Still, the key topics are centered around core issues in regional science.

Figure 1 presents the results of a so-called "term analysis" in titles, keywords and abstracts of published papers in the journal over the period 2010-2019. It is clear that topics related to classic issues in regional science, such as issues related to the distribution of economic activity, distance, costs, competition, migration, location choice, convergence, agglomeration, productivity, are very common. However, 


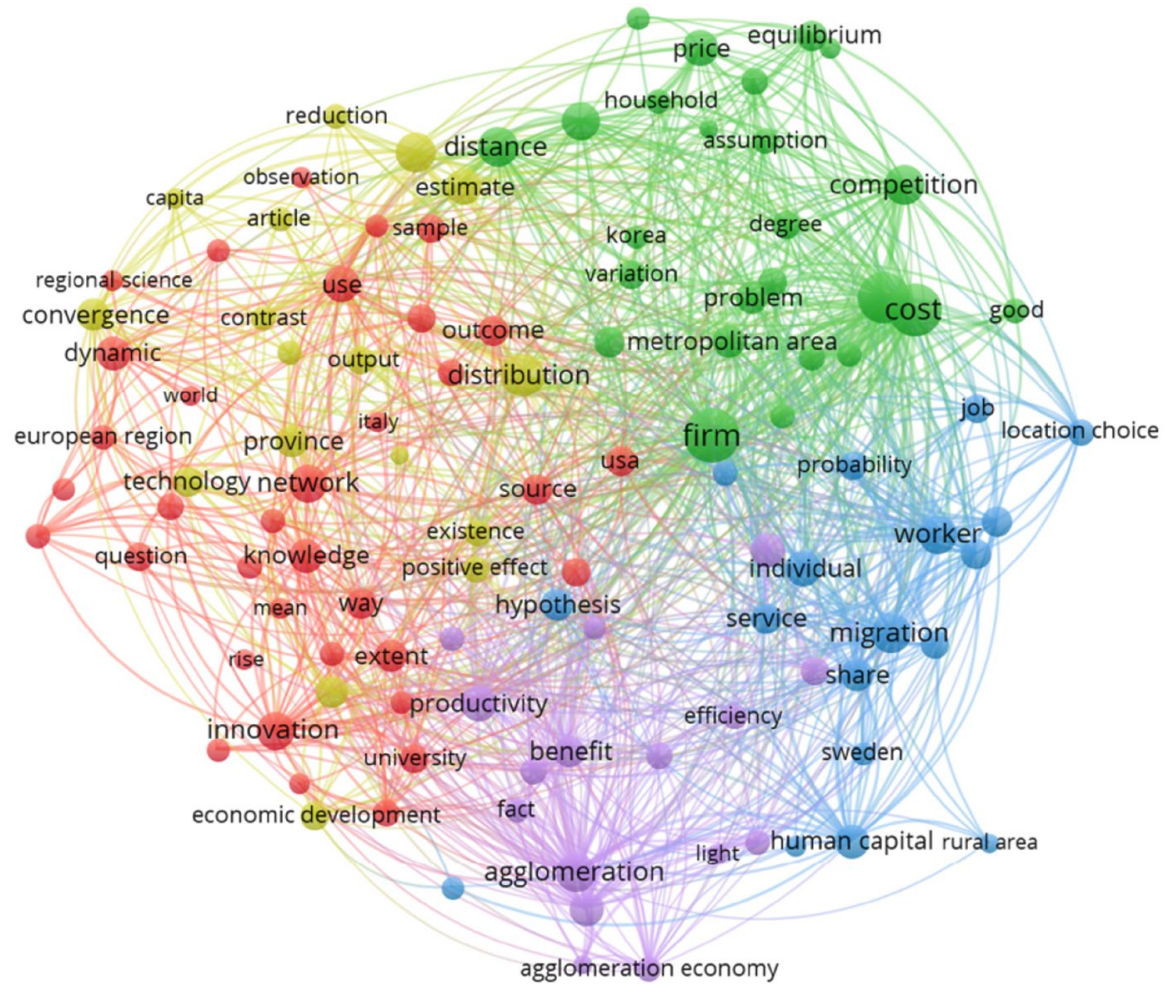

Fig. 1 Term analysis of published papers in Annals of Regional Science 2010-2019

we also see that papers recently published in the journal frequently assess issues related to innovation, as reflected by terms such as innovation, technology, networks, knowledge and human capital.

Another way to describe the broad coverage of the journal is to look at the composition of the most downloaded and the cited papers in the journal in recent years. Table 1 presents the five most downloaded as well as the five most cited papers published in Annals of Regional Science in either 2017 or 2018.

Looking at the most downloaded papers, we see that the majority of the papers (3 out of 5) deals with the topic of resilience (Bristow and Healy 2018; Kitsos and Bishop 2018; Di Caro and Fratesi 2018). There are at least two explanations for this. One is that issues of resilience of regions as well as cities gained significant interest in the wake of the financial crisis prior to 2010. It became clear that we need more research on how regions can withstand major economic shocks and manage turbulent times while maintaining jobs, incomes as well as the wellbeing of their residents. A second reason is that we published a high-quality special issue on resilience that was initiated and edited by Paolo Di Caroa and Ugo Fratesi. The other two papers on the list, i.e., de Vos et al. (2018) and Crescenzi 


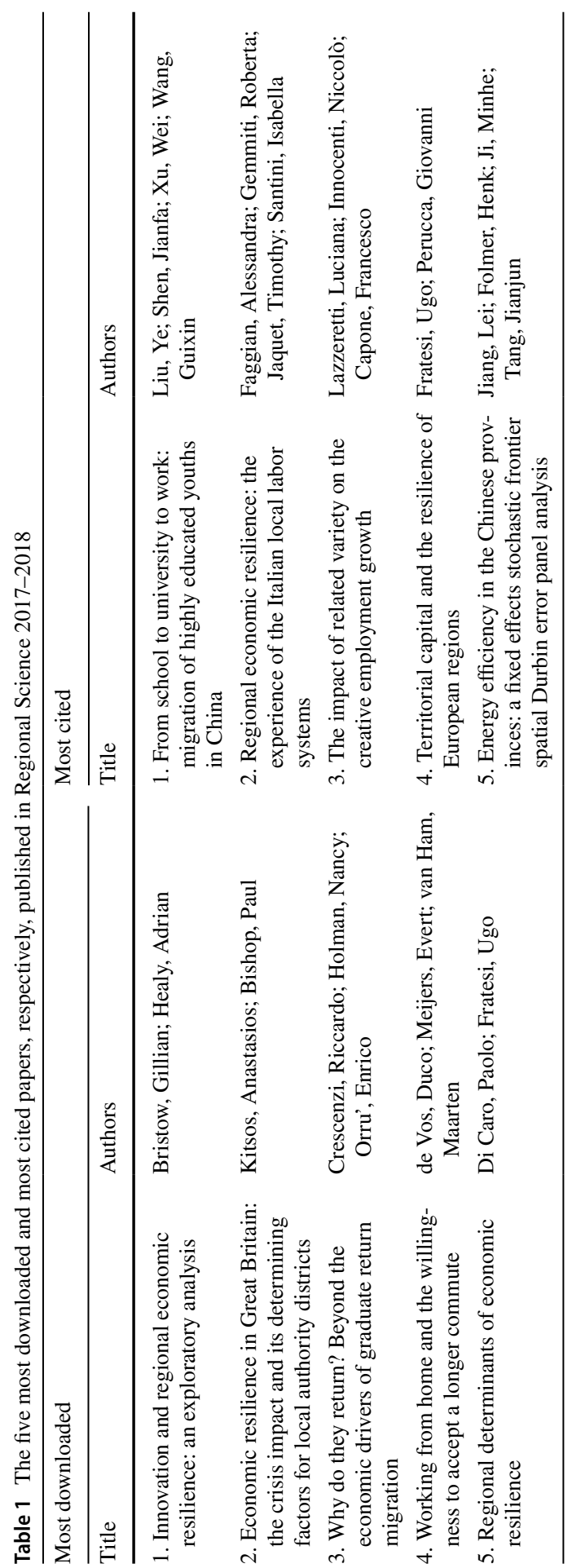


Table 2 Distribution of publications and citations by country of residence of authors, top 10 countries

\begin{tabular}{|c|c|c|c|c|c|}
\hline \multicolumn{3}{|l|}{ Since 1967} & \multicolumn{3}{|l|}{ Since 2009} \\
\hline Country & $\begin{array}{l}\text { Publications } \\
\text { (fraction in \%) }\end{array}$ & $\begin{array}{l}\text { Citations (frac- } \\
\text { tion in } \% \text { ) }\end{array}$ & Country & $\begin{array}{l}\text { Publications } \\
\text { (fraction in \%) }\end{array}$ & $\begin{array}{l}\text { Citations } \\
\text { (fraction } \\
\text { in } \% \text { ) }\end{array}$ \\
\hline USA & 38 & 31 & USA & 22 & 20 \\
\hline Netherlands & 5 & 11 & Spain & 8 & 5 \\
\hline Canada & 5 & 2 & China & 8 & 6 \\
\hline Germany & 4 & 7 & Italy & 6 & 8 \\
\hline UK & 4 & 6 & Germany & 6 & 10 \\
\hline Japan & 4 & 3 & Netherlands & 6 & 14 \\
\hline Spain & 4 & 4 & Sweden & 5 & 6 \\
\hline Sweden & 4 & 4 & Japan & 5 & 3 \\
\hline Italy & 3 & 5 & South Korea & 4 & 2 \\
\hline China & 3 & 4 & UK & 4 & 4 \\
\hline Sum & 74 & 77 & Sum & 73 & 78 \\
\hline
\end{tabular}

For co-authored papers, the country of origin of each author country of origin is counted

and Holman (2017), deal with return migration of university graduates and longdistance commuting, respectively, both being key issues in regional science.

The most cited papers among those published in 2017 or 2018 cover a variety of topics. The paper by Liu et al. (2017) conducts an empirical analysis of migration patterns of the young and educated in China. Faggian et al. (2018) analyze regional economic resilience of local labor markets in Italy. The third most cited paper is a paper by Lazzeretti et al. (2017), and they present an empirical analysis of how related variety in regions influence creative employment growth. Another highly cited paper is Fratesi and Perucca (2018) who assess the relationships between territorial capital and economic resilience in European regions. Moreover, Jiang's et al. (2017) analysis of energy efficiency in Chinese provinces is also among the most cited recent papers in the journal. This reflects that the most cited papers are not clustered around any core topic, but rather cover a variety of issues in regional science.

\subsection{Authors from all over the world}

Annals of Regional Science receives submissions from authors based in countries all over the world, though the vast majority of authors are based in the USA or Europe. In recent years, we have witnessed an increased number of submissions as well as published papers from authors based in Asia, in particular China and South Korea.

Table 2 shows the top 10 countries in terms of the country of origin of authors of publications in the journal since 1967 and 2009, respectively. The table shows the fraction (in \%) of the total number of publications from each country in the top 10 as well as the fraction of citations that pertains to published articles from authors in those countries. 
The top 10 countries account for over $70 \%$ of all published papers and almost $80 \%$ of the total number of citations to articles published in the journal. This is true irrespective of whether we look at the longer period from 1967 or more recently from 2009. However, there are rather clear changes over time in terms of the ranking of countries as well as in terms of the concentration of publications and citations.

First, authors in the USA dominate in both periods, but in more recent years, USbased authors account for a much smaller share of the total number of publications. For the whole period from 1967 until today, almost $40 \%$ of all the published papers had US-based authors and these papers accounted for about $30 \%$ of the citations to the papers in the journal. For the more recent period, from 2009 until today, those figures have changed to $22 \%$ and $20 \%$, respectively. Among the top 10 countries, the distribution of both publications and citations has become more even.

Second, the top 10 countries are the same in both periods, with two exceptions. When looking at published papers since 2009, Canada is no longer in the top 10 . Instead, it is South Korea that enters the top group by accounting for about $4 \%$ of the published papers since 2009.

Third, China, Spain and Italy have both at least doubled their fraction of papers published in the journal. Today, authors from China and Spain each account for about $8 \%$ of the published articles in Annals of Regional Science and Italy about $6 \%$. The other countries in the top 10, i.e., Sweden, Japan, UK, Netherlands and Germany, have a similar fraction of papers in both periods.

Fourth, it may be noted that authors from the Netherlands and Germany stand out in the sense that their fraction of citations is much higher than their fraction of published papers. This implies that published papers from authors based in the Netherlands and Germany typically become highly cited. Since 2009, for instance, $6 \%$ of the total number of publications come from authors based in the Netherlands. At the same time, published papers from authors based in the Netherlands account for $14 \%$ of the total number of citations. For Germany, the corresponding figures are $6 \%$ and $10 \%$, respectively. We believe this reflects the strong position of regional science as a field of research in both the Netherlands and Germany.

\subsection{Continued publication of timely and high-quality special issues}

Annals of Regional Science has a long history of publishing timely and relevant high-quality special issues on certain topics in regional science. In recent years, we have also published several special issues that have attracted significant interest from our readers. These include (guest editors in parentheses):

- Impact of air pollution on regional economies in East Asia (Kyung-Min Nam and Heeyeun Yoon)

- Spatial aspects of entrepreneurship and innovation (Xiyi Yang and David Emanuel Andersson)

- Innovative potential for development of Europe's neighboring countries and regions (Edward M. Bergman and Attila Varga)

- Regional determinants of economic resilience (Paolo Di Caro and Ugo Fratesi) 
- Youth and graduate migration (Alessandra Faggian, Jonathan Corcoran and Francisco Rowe)

There are also a several high-quality special issues in the pipeline on topics such as social capital and rural development, progress in spatial econometrics and spatial statistics as well as stated and revealed locational preferences of firms. We EICs are committed to continue to attract and publish high-quality special issues on relevant and timely topics and encourage researchers to contact us with proposals of special issues.

\section{Concluding remarks}

We believe that the short overview shows that Annals of Regional Science is in good shape that the trajectory of the journal is positive. We EICs are committed to work to maintain and to further develop the journal's positive development.

Recent developments in our societies also illustrate that issues in which the spatial dimension plays a fundamental role are more relevant than ever. For example, in several countries the political and economic polarization between urban and rural areas are rising, and issues of the geography of growth, jobs and well-being are high on the policy agenda in many countries. Likewise, new technology, not least digitalization, puts pressure on local labor markets, and there are rising concerns that a future wave of automation of certain types of job tasks will constitute a major challenger for, in particular, many mid-sized cities and rural areas in both developed and undeveloped countries. Moreover, combating climate change is a major twenty-first century challenge and issues related to how regions and cities can work to reduce climate footprints are critical. These are just examples of issues in which theoretical as well as empirical research in regional science can make substantial impact. We look forward to seeing a great number of submissions to Annals of Regional Science that address these and other relevant issues that push the research frontier forward and contribute to develop knowledge of how pressing issues for regions, cities and societies at large can be addressed.

\section{References}

Bristow G, Healy A (2018) Innovation and regional economic resilience: an exploratory analysis. Ann Reg Sci 60(2):265-284

Crescenzi R, Holman N (2017) Why do they return? Beyond the economic drivers of graduate return migration. Ann Reg Sci 59(3):603-627

de Vos D, Meijers E, van Ham M (2018) Working from home and the willingness to accept a longer commute. Ann Reg Sci 61(2):375-398

Di Caro P, Fratesi U (2018) Regional determinants of economic resilience. Ann Reg Sci 60(2):235-240

Faggian A, Gemmiti R, Jaquet T, Santini I (2018) Regional economic resilience: the experience of the Italian local labor systems. Ann Reg Sci 60(2):393-410

Fratesi U, Perucca G (2018) Territorial capital and the resilience of European regions. Ann Reg Sci 60(2):241-264 
Jiang L, Folmer H, Ji M, Tang J (2017) Energy efficiency in the Chinese provinces: a fixed effects stochastic frontier spatial Durbin error panel analysis. Ann Reg Sci 58(2):301-319

Kitsos A, Bishop P (2018) Economic resilience in Great Britain: the crisis impact and its determining factors for local authority districts. Ann Reg Sci 60(2):329-347

Kohlhase JE (2019) In memoriam: Roger Reece Stough (1940-2019). Ann Reg Sci 63(3):375-376

Lazzeretti L, Innocenti N, Capone F (2017) The impact of related variety on the creative employment growth. Ann Reg Sci 58(3):491-512

Liu Y, Shen J, Xu W, Wang G (2017) From school to university to work: migration of highly educated youths in China. Ann Reg Sci 59(3):651-676

Publisher's Note Springer Nature remains neutral with regard to jurisdictional claims in published maps and institutional affiliations. 